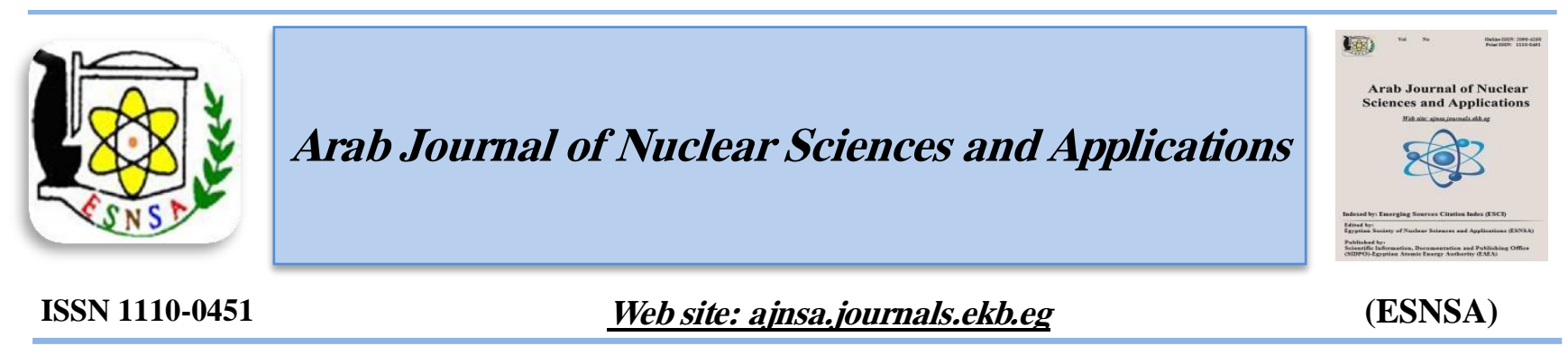

\title{
Development of a Radio Frequency Coupled Broad Beam Ion Source for Material Processing
}

\author{
A. Hassan ${ }^{1}$, M. Gamal ${ }^{1}$, S. G. Zakhary ${ }^{1}$,L.O. Abdelbaset $^{2}$ and M. El Sayed Hanafy ${ }^{3}$ \\ ${ }^{1}$ Accelerators \& Ion Sources Department, Nuclear Research Center, Atomic Energy Authority, Cairo, Egypt \\ ${ }^{2}$ Physics Department, Faculty of Science, Aswan University \\ ${ }^{3}$ Physics Department, Faculty of Science, Zagazig University
}

Received $11^{\text {th }}$ Jan. 2018
Accepted $29^{\text {th }}$ Jan. 2018

Received $11^{\text {th }}$ Jan. 2018
Accepted $29^{\text {th }}$ Jan. 2018

\begin{abstract}
The present work presents the development of a radio frequency (RF) broad beam ion source for generating a high brightness ion beam for material processing. The source is able to deliver ion beams energy from 100 to $2000 \mathrm{eV}$ with beam currents from $100 \mu \mathrm{A}$ up to $25 \mathrm{~mA}$. The beam divergence does not exceed 8 degrees when using nominally flat grid. The extracted ion current from a plasma source depends on the plasma parameters particularly the electron density and the electron temperature of the plasma. Optical Emission Spectroscopy (OES) is used to determine the plasma electron density and temperature. The effects of argon filling pressures and RF power on electron temperature and density of plasma parameters are investigated. The electron density of argon plasma is between $4 \times 10^{11}$ and $7 \times 10^{12}$ $\mathrm{cm}^{-3}$, whereas electron temperature $0.6-5 \mathrm{eV}$ at pressures from $5 \times 10^{-4}$ to $8.5 \times 10^{-3}$ mbar over the RF powers deposited within the plasma from 25 to $200 \mathrm{~W}$. The ion source is installed on a homemade accelerating tube. The beam optics is extensively studied with space charge compensation by Transport code. A solenoid magnet located between the ion source and the accelerating tube is used to focus and control the beam divergence. The performance of the accelerating facility is reported and applications for material modification are examined.
\end{abstract}

Keywords: Radio frequency ion source, Optical emission spectroscopy, Ion beam processing

\section{Introduction}

Broad beam ion sources are widely used in material processing for surface cleaning, etching, and thin film growth. The ion beam surface treatments were used commercially for the reduction wear, especially in expensive molding tools. [1] Broad beam ion sources are of increasing interest for electronic and semiconductor industry, particularly, in the sub-micrometer range through the implantation and deposition processes [2]. The advantage of ion sources compared with other plasma devices is, that the important parameters of the ions which are angle of incidence on the target, ion energy, and ion current can be chosen independently.
Radio-frequency ion sources are widely employed in direct voltage accelerators, due to their long life because of the absence of filament, and good beam characteristics and satisfactory working conditions. The Argon radio-frequency (RF) discharge plasma at low pressures is extensively used in the processing of materials [1-3]. The parameters and performance of the extracted ion beams are strongly influenced by the geometry of the electrode system and the plasma parameters inside the ion source chamber [4-6].

In the present study, the operational characteristics and plasma diagnostics of the developed RF ion source are introduced. A simulation and experimental study of an accelerating facility

Corresponding author: amin.hassan@eaea.org.eq

DOI: 10.21608 /ajnsa.2018.2616.1038

(C) Scientific Information, Documentation and Publishing Office (SIDPO)-EAEA 
begins from the extraction electrode system, the focusing lens and the accelerating tube is investigated. This accelerating facility is going to be utilized for material processing, so the influence of argon ion irradiation at various energies is examined.

\section{Experimental Results and Discussion}

The RF ion source is schematically shown in Figure (1a). It consists of a cylindrical Pyrex glass, $50 \mathrm{~mm}$ diameter and $55 \mathrm{~mm}$ long, with two copper rings wrapped around and used as the RF antenna. The antenna is supplied by a $0-600 \mathrm{~W}, 13.56$ $\mathrm{MHz}$ RF generator (AG 0613) complete with an automatic matching network (AIT/MIT-600) to maximize the power transfer efficiency from the $\mathrm{RF}$ generator to the plasma. Figure (1b) shows photographic image of the radio frequency ion source with extraction system and permanent magnet.

A ring permanent magnet of $0-180$ Gauss field strength along the source axis is installed. This axial magnetic field confines the electrons and prolongs their effective path within the discharge tube. This increases the number of electron collisions with gas atoms and molecules and successively, will increase the chances of ionization and reduces diffusion losses toward the discharge walls.

The gas is introduced to the ion source through a fine control needle valve, which regulates the flow rate for a variety of discharge gases. The ion source is equipped, at the upper end, with a gas inlet and a stainless-steel grid at the lower end. The retarding potential electrode is a tungsten rod of 2 $\mathrm{mm}$ thickness. The grid cathode is made from stainless steel of $2 \mathrm{~mm}$ thickness. The apertures of the grid are arranged on sequent concentric circular orbits. The diameter of the grid holes is increased with the increase of the orbit radius [7]. These apertures are arranged to produce a wide and uniform beam density distribution with the utilization of perveance matching to the normal Gaussian distribution [7, 8], see reference [7] for more details.

The retarding electrode is connected to positive potential while the grid cathode is held at earth potential. The potential difference between the retarding electrode and the grid creates a field gradient that acts to draw ions from the plasma and through the holes within the grid. The multiple 'beamlets' combine to form one broad ion beam which emerges into the chamber. The excited atoms and ions in the discharge plasma create a unique emission spectrum specific to each element. The plasma parameters, including the electron density and temperature have significant influences on the characteristics of the ion extraction process [9].

Optical emission spectroscopy plasma diagnostics Optical emission spectroscopy (OES) is a noninstructive [10] and simple technique widely used for low temperature plasma diagnostics. OES is based on analyzing the light emitted by neutral or ionized atoms, radicals, or molecules [11]. It is conveniently employed for determining the plasma parameters as electron temperature and density by the so-called the two-line emission ratio technique. The optical emission spectra of the RF plasma source are detected by a fiber optic spectrometer (Avantes AvaSpec 3648) with a $0.3 \mathrm{~nm}$ spectral resolution in the range from 200 to $1100 \mathrm{~nm}$ was used. This spectrometer is designed with 3648pixel CCD Detector Array, collimating and focusing mirror and diffraction grating. The collimating lens at the end of the optical fiber is fastened to the plasma source straightly in radial direction as shown in Figure (2). With slit size 10 $\mu \mathrm{m}$ and with gratings $600 \mathrm{l} / \mathrm{mm}$ it is possible to operate in the spectral range $392-944 \mathrm{~nm}$ with resolution $0.3-0.36 \mathrm{~nm}$. The connection to your computer is done through USB2 at $480 \mathrm{Mbps}$ [12].

Figure (3) shows an example of the optical emission spectrum of argon plasma from 200 to $1100 \mathrm{~nm}$ recorded at a filling pressure of $3 \times 10^{-4}$ mbar and radio frequency power of $75 \mathrm{~W}$. The intensive spectral lines of argon were found within the region between 690 and $970 \mathrm{~nm}$. These spectroscopic lines are in agreement with the atomic data base of NIST [13]. The electron density $\left(n_{e}\right)$ and temperature $\left(T_{e}\right)$ of the RF plasma source are determined based on the method of the relative intensities of two spectral lines of the same atomic species. This is expressed by [14]:

$$
\mathrm{KT}_{\mathrm{e}}=\frac{\mathrm{E}_{1}-\mathrm{E}_{2}}{\ln \left(\frac{\mathrm{A}_{1} \mathrm{~g}_{1} \lambda_{2} \mathrm{I}_{2}}{\mathrm{~A}_{2} \mathrm{~g}_{2} \lambda_{1} \mathrm{I}_{1}}\right)}
$$

Arab J. Nucl. Sci. \& Applic. Vol. 52, No. 1 (2019) 
where $I_{1}, \lambda_{1}, g_{1}$ and $A_{1}$ are the total intensity, the wavelength, the statistical weight and the transition probability, respectively of one line with $E_{1}$ its

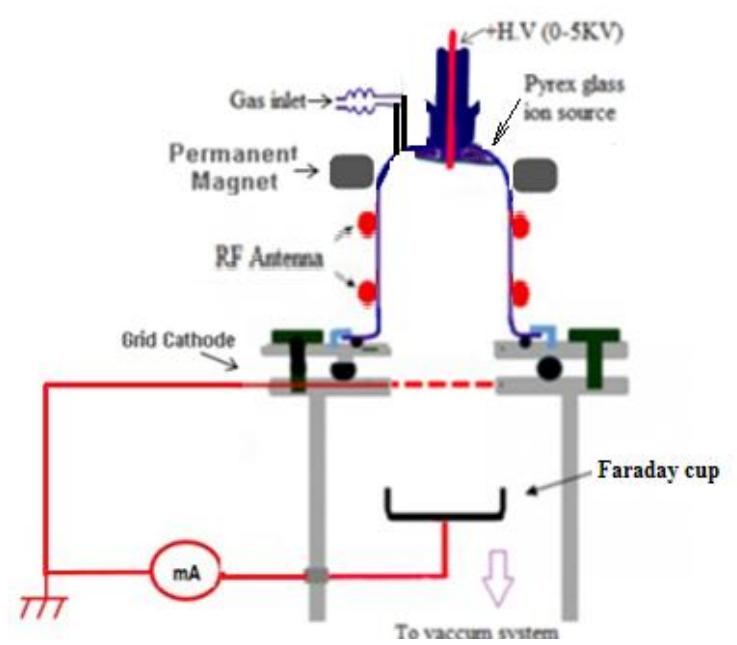

Figure. (1) The radio frequency ion source with extraction system and permanent magnet (a) Schematic diagram and (b) photographic image excitation energy. The corresponding quantities for the other line are $\mathrm{I}_{2}, \lambda_{2}, \mathrm{~g}_{2}$, and $\mathrm{E}_{2}$.

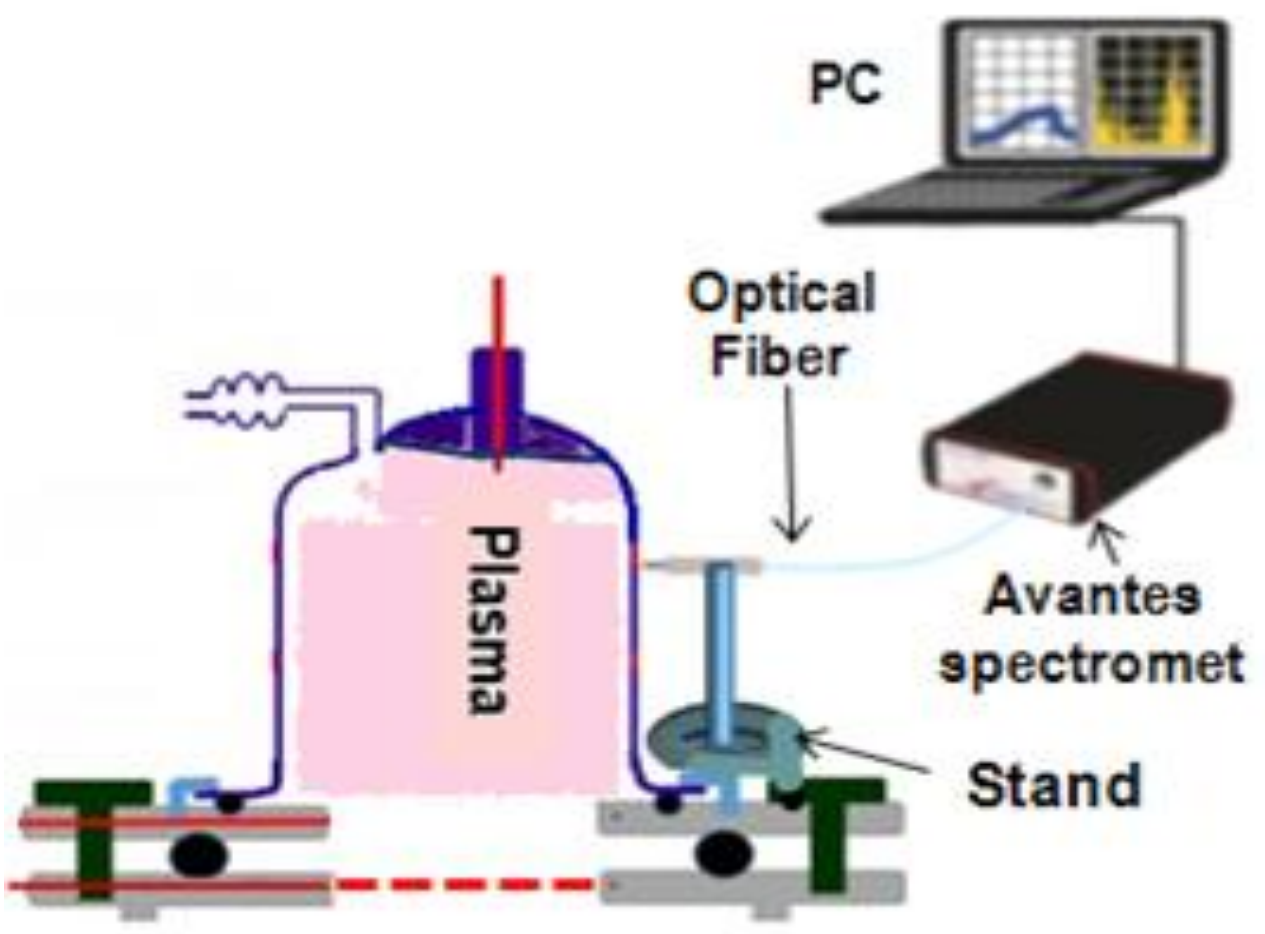

Figure (1) Experimental setup for OES measurements 


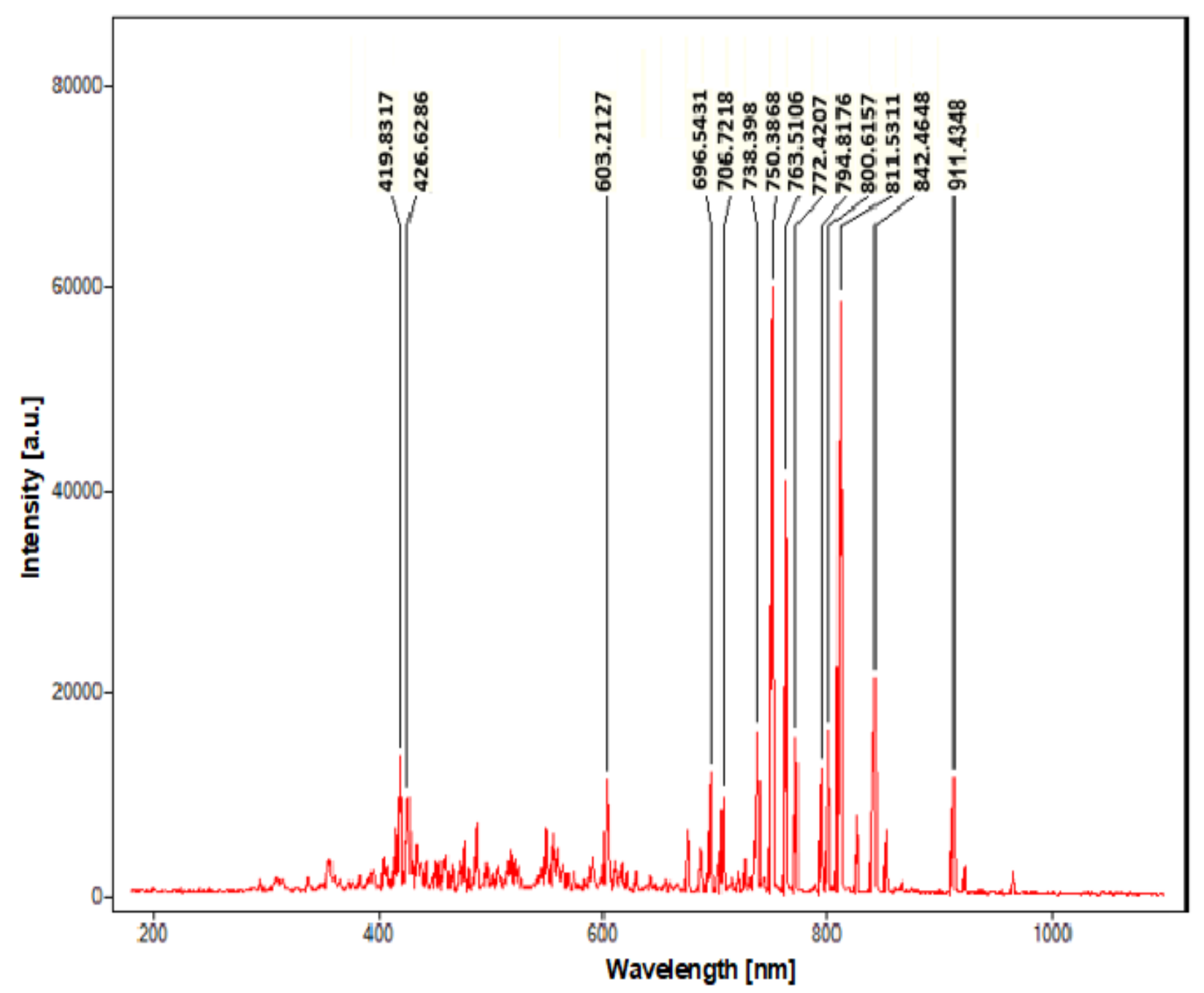

Figure (2) Optical emission spectrum of argon plasma from 200 to $1100 \mathrm{~nm}$ recorded at a filling pressure of $3 \times 10^{-4}$ mbar and RF power of $75 \mathrm{~W}$

The electron temperature $\mathrm{T}_{\mathrm{e}}$ is determined from the intensity ratio of two Ar-I lines at 706.72 and $750.39 \mathrm{~nm}$. The electron density of the argon plasma was evaluated from the intensity ratio of Ar-I at $772.38 \mathrm{~nm}$ to Ar-II at $738.04 \mathrm{~nm}$ through Boltzmann and Saha equation given below: ${ }^{[15,16]}$

$$
\begin{gathered}
\mathrm{n}_{\mathrm{e}}=\frac{(2 \pi \mathrm{mKT})_{\mathrm{e}}^{\frac{3}{2}}}{\mathrm{~h}^{3}}\left\{\frac{2 \mathrm{~A}^{+} \mathrm{g}^{+} \lambda^{0} \mathrm{I}^{0}}{\mathrm{~A}^{0} \mathrm{~g}^{0} \lambda^{+} \mathrm{I}^{0}}\right\} \\
\operatorname{Exp}\left[\frac{\mathrm{E}^{+}-\mathrm{E}^{0}+\mathrm{E}_{\mathrm{i}}^{0}-\Delta \mathrm{E}_{\mathrm{i}}^{0}}{\mathrm{~K} \mathrm{~T}}\right]
\end{gathered}
$$

Where $0,+$ corresponding to $\mathrm{Ar}-\mathrm{I}$ and $\mathrm{Ar}-\mathrm{II}$ respectively, and $\mathrm{T}_{\mathrm{ex}}, \mathrm{E}, E_{i}^{0}$, and $\Delta E_{i}^{0}$ represent excitation temperature, energy of emitting level, ionization energy of the neutral atom, lowering of ionization energy respectively.

\section{Effect of RF power}

The Intensity of argon plasma spectrum at different RF powers is shown in Figure (4). This figure shows that argon spectral lines intensity increased as RF power is increased.

The electron temperature results are plotted versus $\mathrm{RF}$ power for various argon filling pressure is shown in Figure (5). The electron temperature $T_{e}$ decreased rapidly with increasing pressure from $2.5 \times 10^{-4}$ to $6 \times 10^{-3}$ mbar range and then slightly decreases with further increasing in pressure to 
$2 \times 10^{-2}$ mbar. The slight increase with the pressure could be explained by the RF power is more consumed in ionizing processes much more than raising the temperature. One may deduce that inelastic collisions turn out to be more dominant, leading to a decrease in plasma temperatures. In addition, increasing the applied RF power results in an increase of the electron temperature over the whole pressure range.
The plasma electron density is plotted versus argon filling pressure at different RF powers is depicted in Figure (6). It can be seen that electron plasma densities reach a maximum around $1 \times 10^{-3}$ mbar. Figs. (5 and 6) define the optimum operating values of pressure and RF power that creates a dense plasma which reveals the extraction of a higher intensity ion beam current from the plasma source.

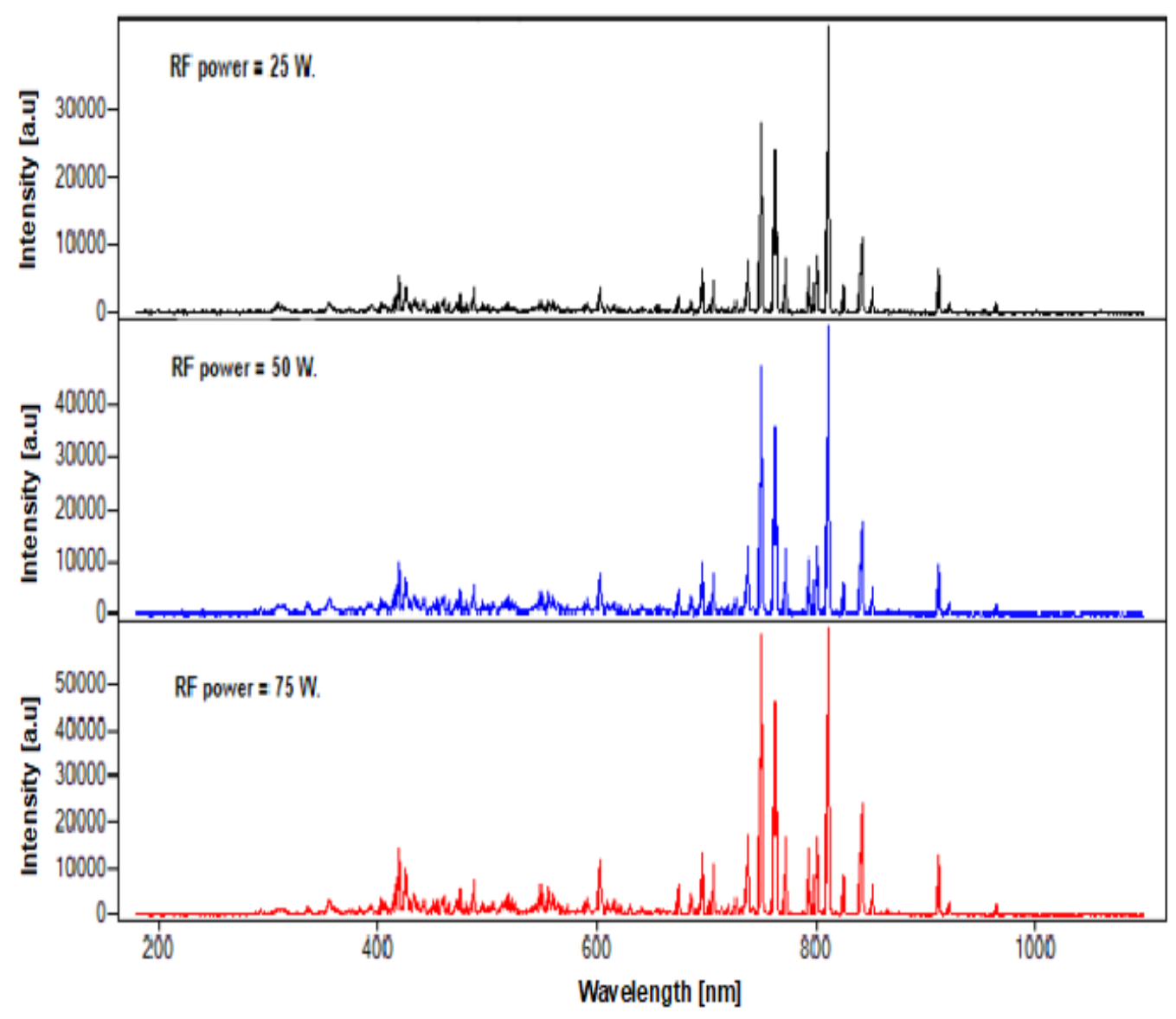

Figure (3) Optical emission spectrum of argon plasma at different RF powers 


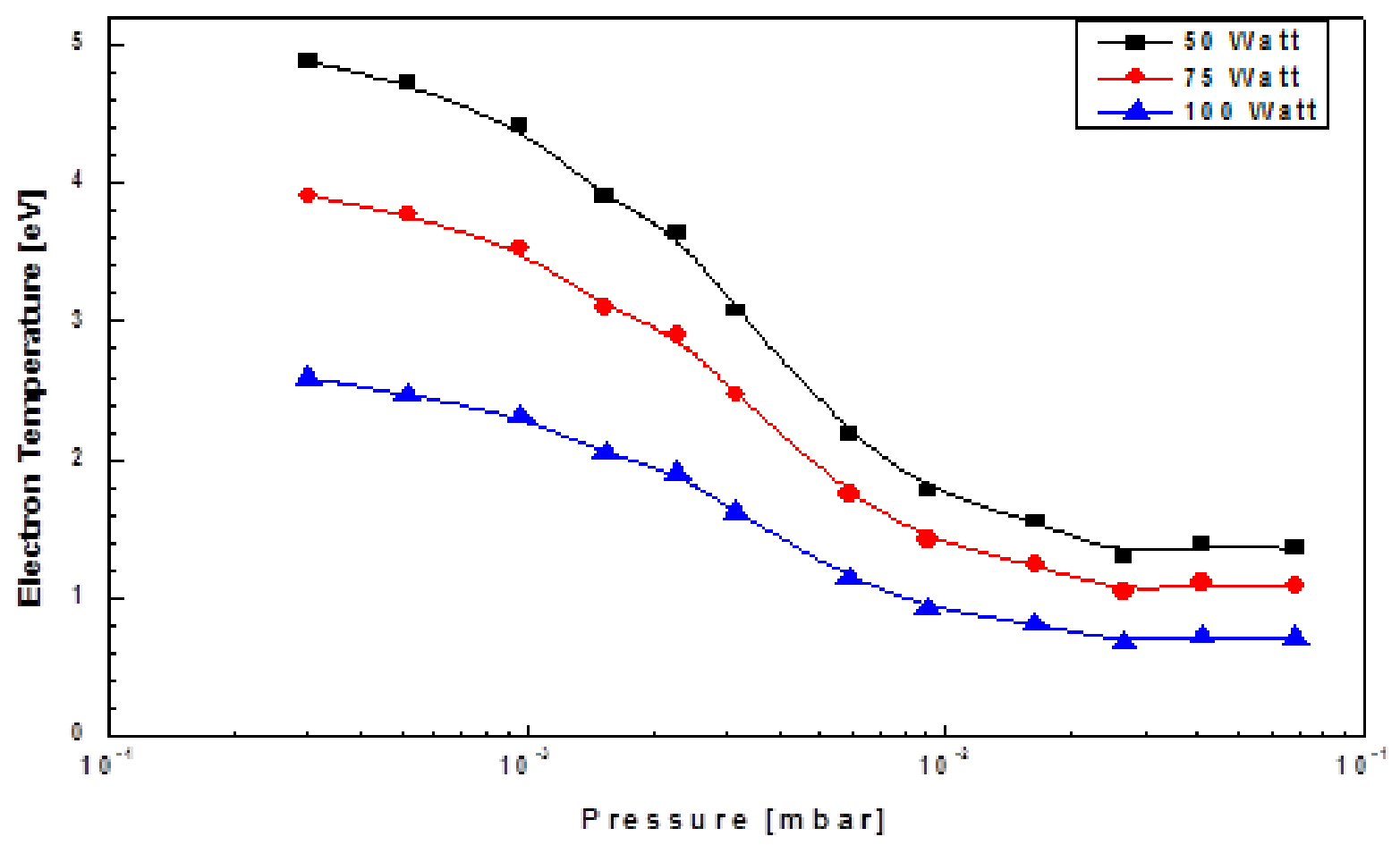

Figure (4) Electron temperature as a function of argon gas pressure at different RF powers

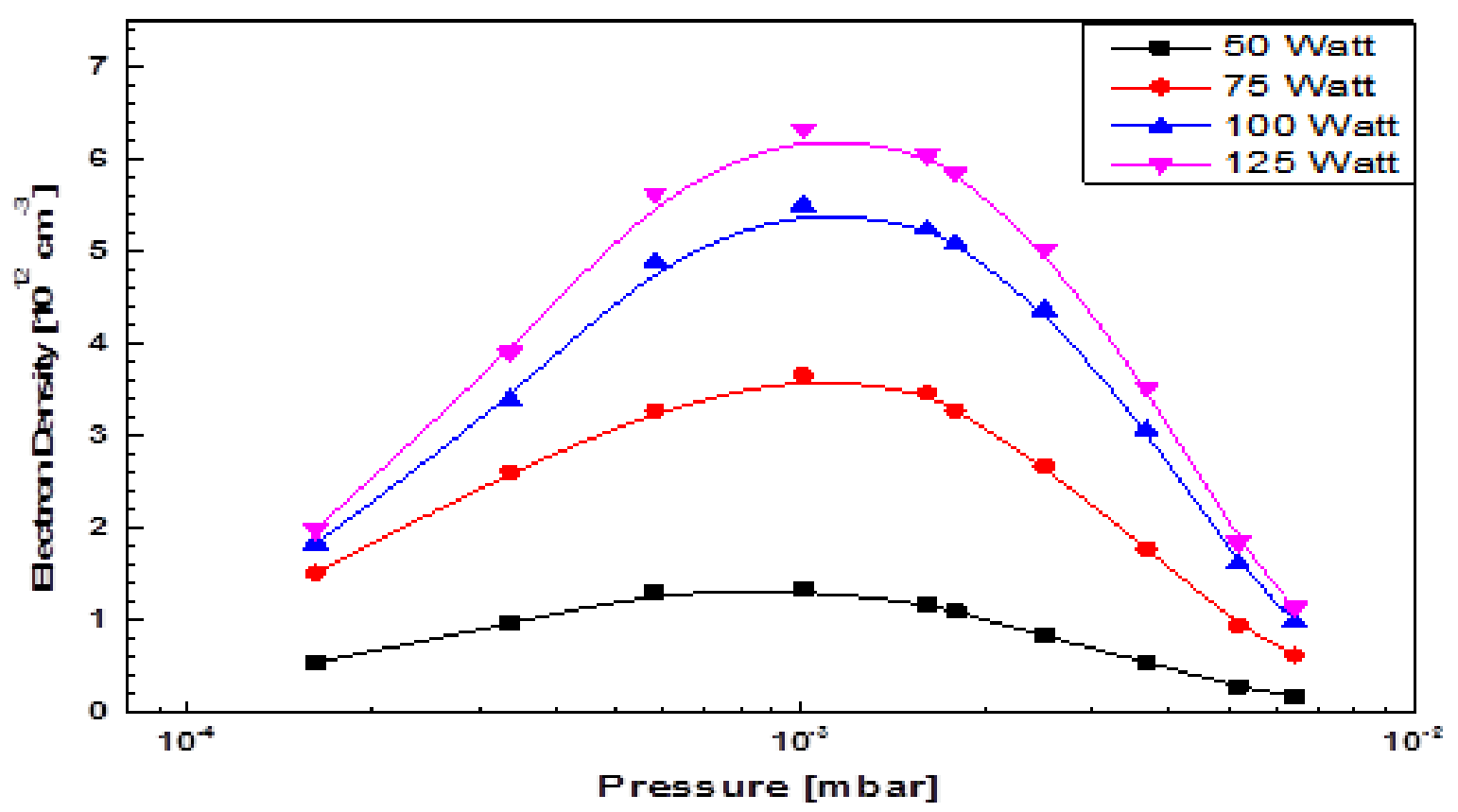

Figure (5) Plasma density versus argon gas pressure at different RF powers 


\section{Ion beam characterization}

The variation of the extracted ion beam current as a function of extraction voltage at different values of RF power and constant pressure of $5.5 \times 10^{-5}$ mbar is shown in Figure (7). The extracted ion beam increased gradually as the extracted potential increased up to $3 \mathrm{kV}$, then the trend of increasing is reduced this is due to the significant potential drop takes place when the electric field intensity in the beam extraction gap is close to breakdown field intensity [17]. Taking into account that the increase of the extraction gap and the hole diameter suppresses the effect of the cathode sheath and ensures both a high ion extraction efficiency and an optimal angular divergence of the ion beam. The space-charge limited ion beam current density is given by the Child-Langmuir Law [7]:

$$
J=\frac{4 \epsilon_{0}}{9} \sqrt{\frac{2 q}{m}} \frac{V^{\frac{3}{2}}}{d^{2}}
$$

where $\mathrm{J}$ is the ion beam current density, $\mathrm{V}$ is the extraction voltage, $\mathrm{d}$ is the extraction gap distance, $\varepsilon_{0}$ is the permittivity and $\mathrm{q} / \mathrm{m}$ is the charge to mass ratio of the extracted ions. In addition, the total extracted ion beam current can be given by [7]:

$$
\mathrm{I}=\frac{4}{9} \pi \epsilon_{0} S^{2} \sqrt{2 \frac{\mathrm{q}}{\mathrm{m}}} \mathrm{V}^{\frac{3}{2}}
$$

where $\mathrm{I}$ is the extracted ion beam current and $\mathrm{S}=$ $\mathrm{r} / \mathrm{d}$ is the aspect ratio (the ratio of aperture radius $\mathrm{r}$ to the extraction gap distance d) of the extraction aperture geometry. The perveance $\mathrm{P}$ of a multiaperture ion beam source is given by [8]:

$$
p=\frac{1}{V^{3 / 2}}=\frac{j \pi N R^{2}}{4 V^{3 / 2}}
$$

Where $\mathrm{N}$ is the number of apertures and $\mathrm{R}$ is aperture diameter. The extracted ion current is collected on a Faraday cup. The current density at the extraction side is the current collected by the Faraday cup divided by the area of the extraction aperture. The extracted ion beam current as a function of RF power at pressure $5.5 \times 10^{-5}$ mbar and magnetic field of 80 Gauss is shown in Figure (8). It could be seen that the extracted ion beam current increases almost linearly with RF input power. The influence of the RF power on the extracted ion current could be explained. As the RF power is increased, the plasma density increased, and hence more ion current is injected into the plasma sheath resulting in an increased ion beam current. This reveals that by changing RF power, it is possible to make small changes in the beam current for a fixed beam energy. So, it is possible to increase the irradiation fluence for specific samples at the fixed energy. It is observed that as the RF power is increased, the ion beam energy is increased. This increase in ion beam energy can be attributed to the increase in plasma potential near the ion extraction region.

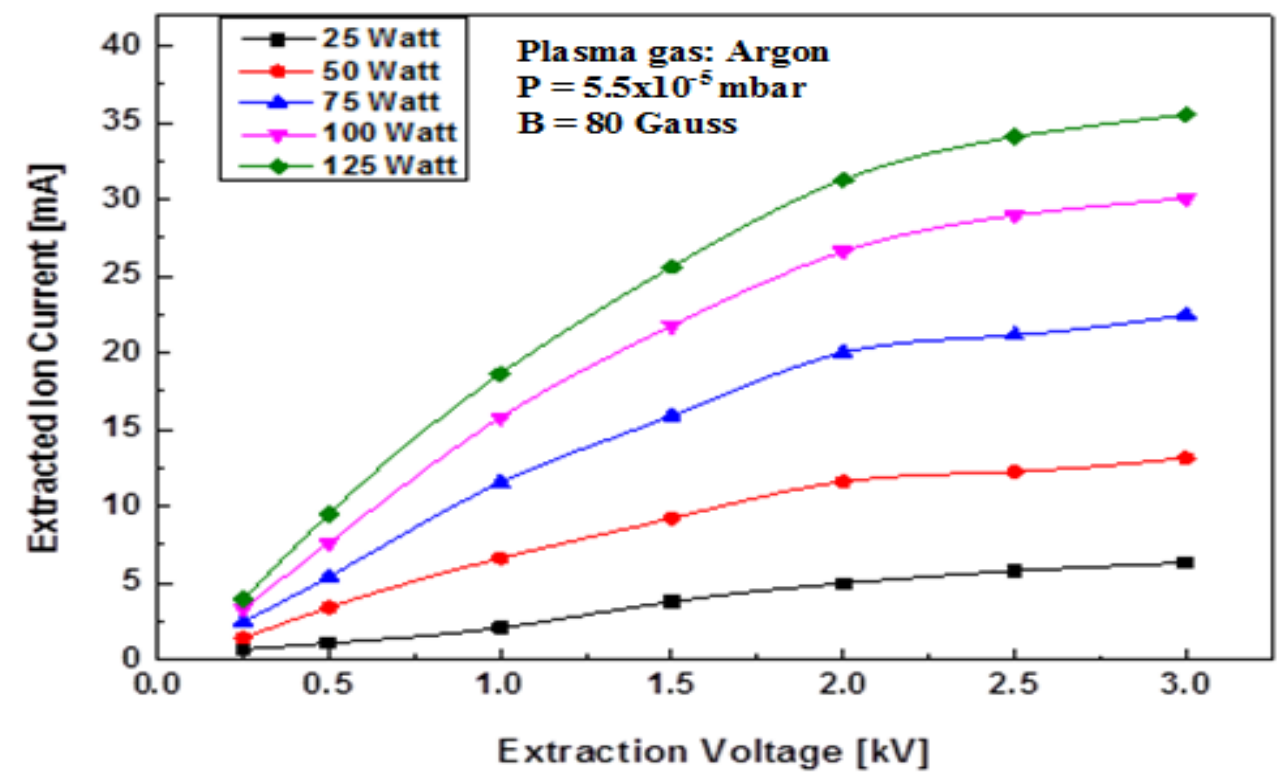

Figure (6) I-V characteristics at different RF powers 


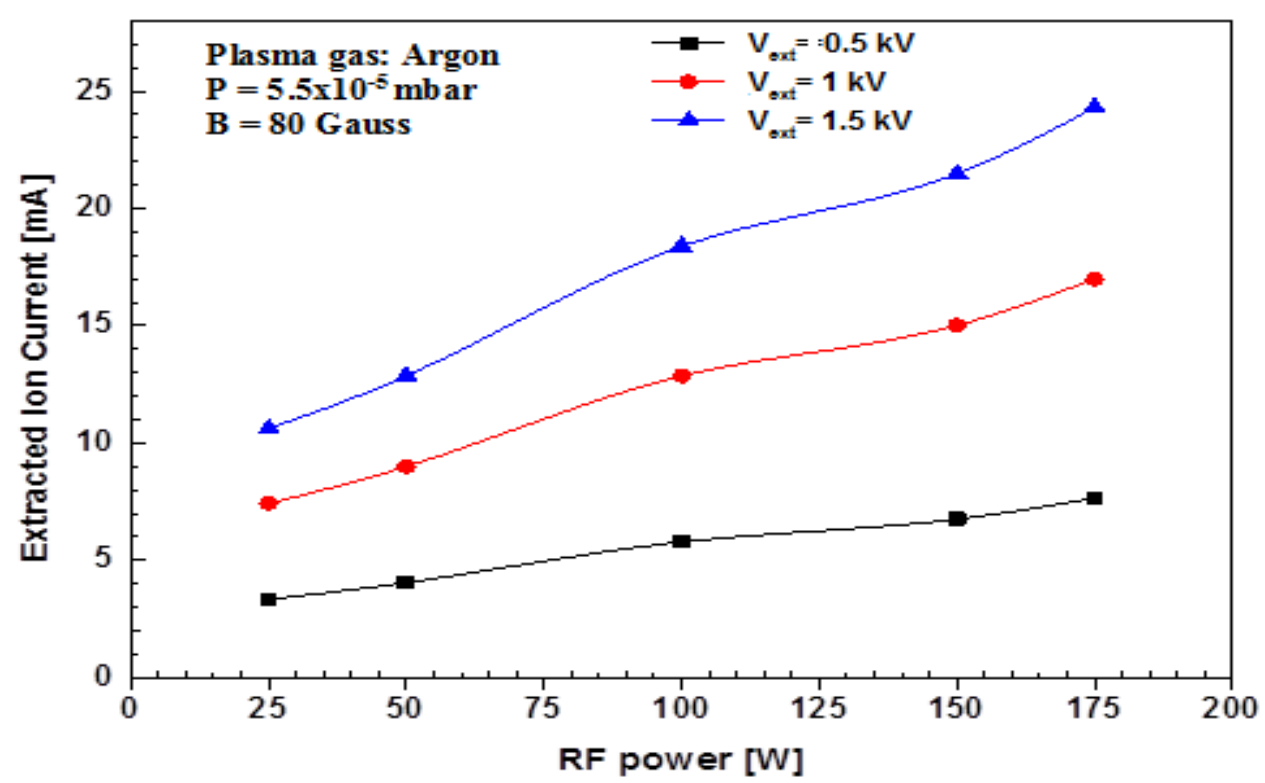

Figure (7) Extracted beam current versus RF power at different extraction voltages

\section{Ion beam acceleration}

Energetic ions play an important role in the materials processing. Ion beam processing is used to synthesize and modify materials, including metals, semiconductors, ceramics and polymers with great precision and control. Ion beam modification of materials involves also its use to alter the composition, structure or properties of the near surface of materials. For these processes, the ions extracted from the plasma source must be accelerated to the desired energy and then transported to the processing chamber. The extracted ion beam is accelerated through a 5-ring accelerating tube. The isolating transformer is used to transfer electric energy to high voltage terminal being at a potential of up to 100 relatives to the earth.

The layout of the accelerating elements is shown in Figure (9). The ion beam is extracted from the plasma source, accelerated to the desired energy and then transported to the target area

The beamline simulation was performed by the Transport [18] program with a graphical interface, which is based on a matrix approach [19-20]. The beamline starts from the outlet of the ion source passing through the solenoid magnets into the accelerating tube to the target area. In this simulation, argon ions of $20 \mathrm{~mA}$ with an energy of $3 \mathrm{keV}$ are leaving the source and refocused with solenoids. Afterwards, they are accelerated to a kinetic energy of $50 \mathrm{keV}$. In this process, the costs and technical difficulties are considered. The beam has been assumed to be fully passing to the target with minimal losses, while the factors of space charge compensation have been held to 0.8 along the beam line. Figure (10) shows the envelopes of $20 \mathrm{~mA} \mathrm{Ar}^{+}$beam current from the ion source to the target in horizontal $\mathrm{x}$ and vertical $\mathrm{y}$ planes respectively.

It is shown that the ion beam current exhibits a narrow waist on front of the accelerating tube. The imaging routine of the waist on target is applied by Transport. The high-current beam is defocused by the space charge forces inside the tube yielding an image of the waist at target which install at $8 \mathrm{~cm}$ behind the last electrode of the accelerating tube.

The results prove a good performance of the accelerating facility. The solenoids magnet field can effectively offset the ion beam divergence caused by the space charge effect. The radius of the envelope is about $6 \mathrm{~cm}$ on the target. Furthermore, for a constant beam current and accelerating potential, the solenoid magnets can control the beam radius at the target. Figure (11) shows the variation of the phase space at different acceleration voltages evaluated at the target. The obtained values reveal that as the acceleration voltage increased the beam emittance is decreased which is due to the focusing effect of the electric lenses formed by the accelerating electrodes. This could be explained in terms of the decrease of the angle of the beam divergence with accelerating

Arab J. Nucl. Sci. \& Applic. Vol. 52, No. 1 (2019) 
voltage according to the equation $\theta=\sqrt{\frac{\mathrm{KT}_{\mathrm{i}}}{\mathrm{eV}}}$, temperature $T_{i}$ accelerated to an axial energy eV where $\theta$ is the ions divergence angle with and $\mathrm{V}$ is the accelerating voltage [21].

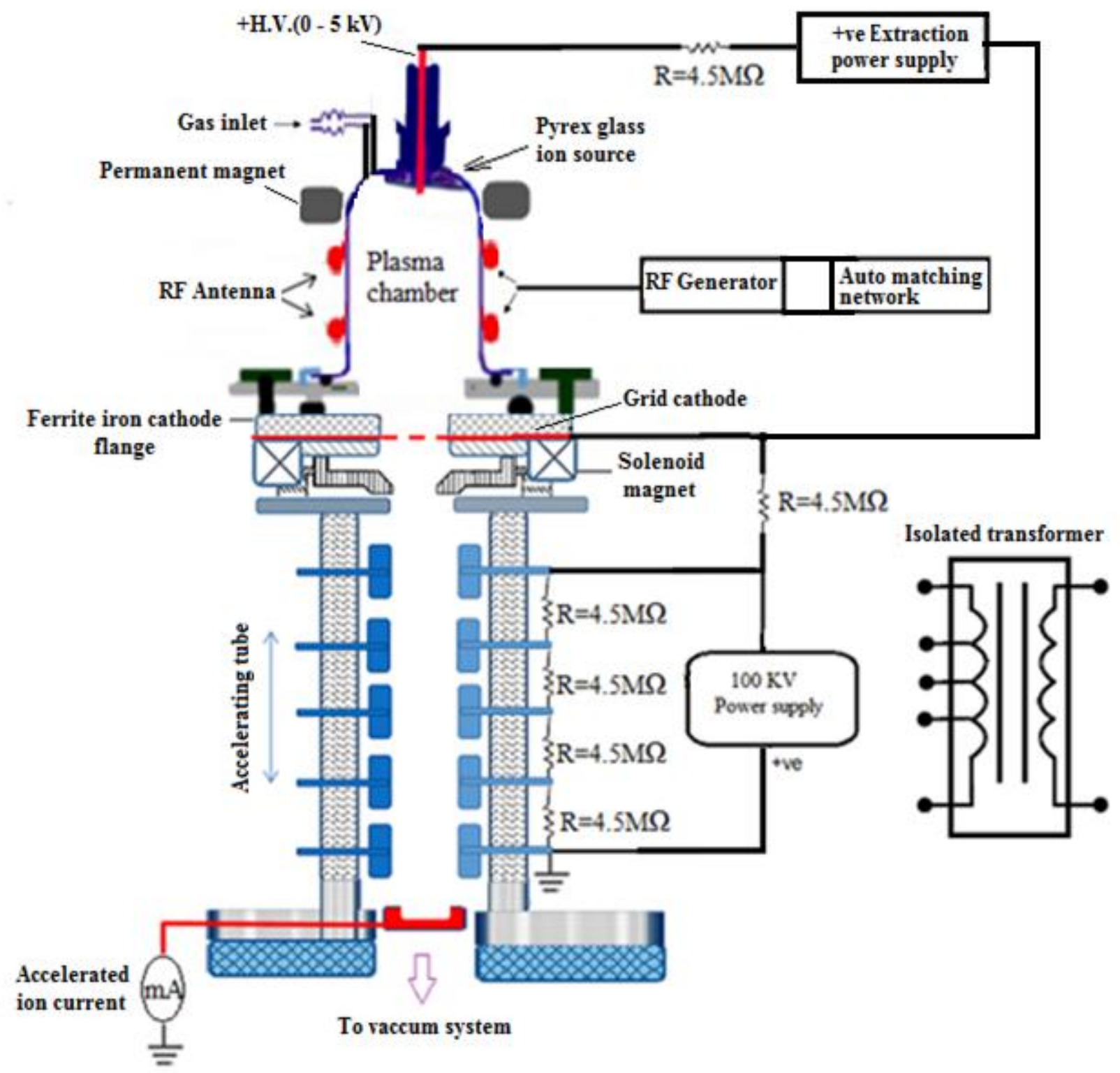

Figure (9) Schematic diagram of the ion beam line of the accelerating facility 


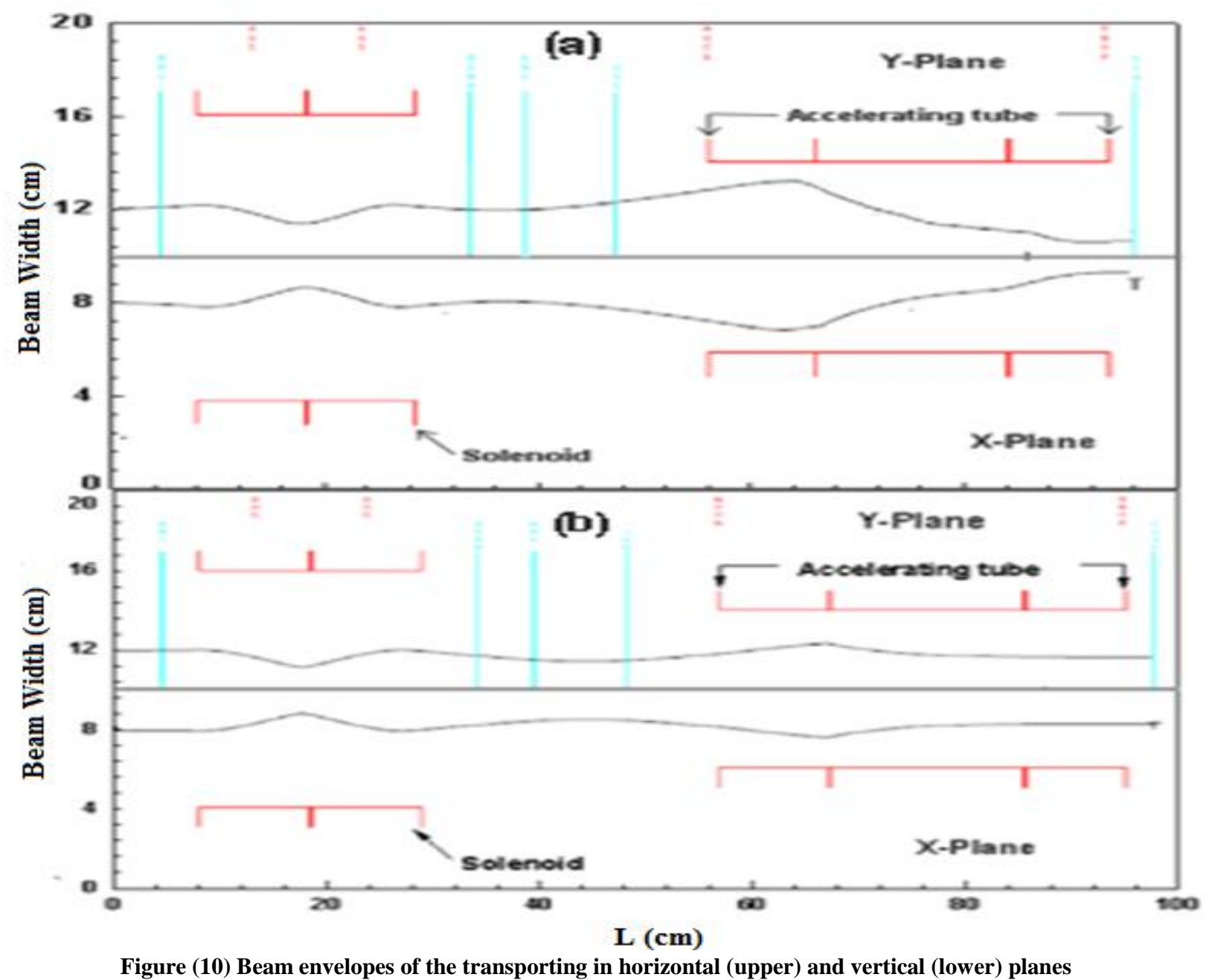

Ion beam processing

The ion beam accelerating facility will be used in material processing. The preliminary results of using the Ar+ ion beams from the accelerating facility for irradiation of polymer samples is reported. A Polyethylene terephthalate (PET) sample, $96 \mu \mathrm{m}$ thick, sold commercially as Hostaphane with $\mathrm{C}_{10} \mathrm{H}_{8} \mathrm{O}_{4}$ chemical formula obtained from A.G. Hoechst Germany, was irradiated at a fluence of $2 \times 10^{-12}$ argon ions of different energies delivered from the accelerator facility. The irradiation process was carried out at room temperature and under pressure equal to $3 \times 10^{-5}$ mbar.

\section{FT-IR analysis of ion beam irradiated PET}

FT-IR spectroscopy gives information about intermolecular interactions corresponding to stretching or bending vibrations of specific bonds. The position at which these peaks appear depends on the bond type. The ion beam irradiation of polymers produces free radicals, ions, and neutral atoms. As a result, many changes on the surface take place; chain scission leading active sites formation. Also, some gases are released which could be trapped in the polymer such as $\mathrm{CO}_{2}, \mathrm{CO}$, $\mathrm{H}$ and $\mathrm{O}_{2}$ [22]. Moreover, the activated surface could undergo oxidation which further leads to the formation of free radicals, followed by chain scission and propagation, and lastly termination (formation of cross-links) [23]. Oxidation could take place from the atomic oxygen or atmospheric air. 

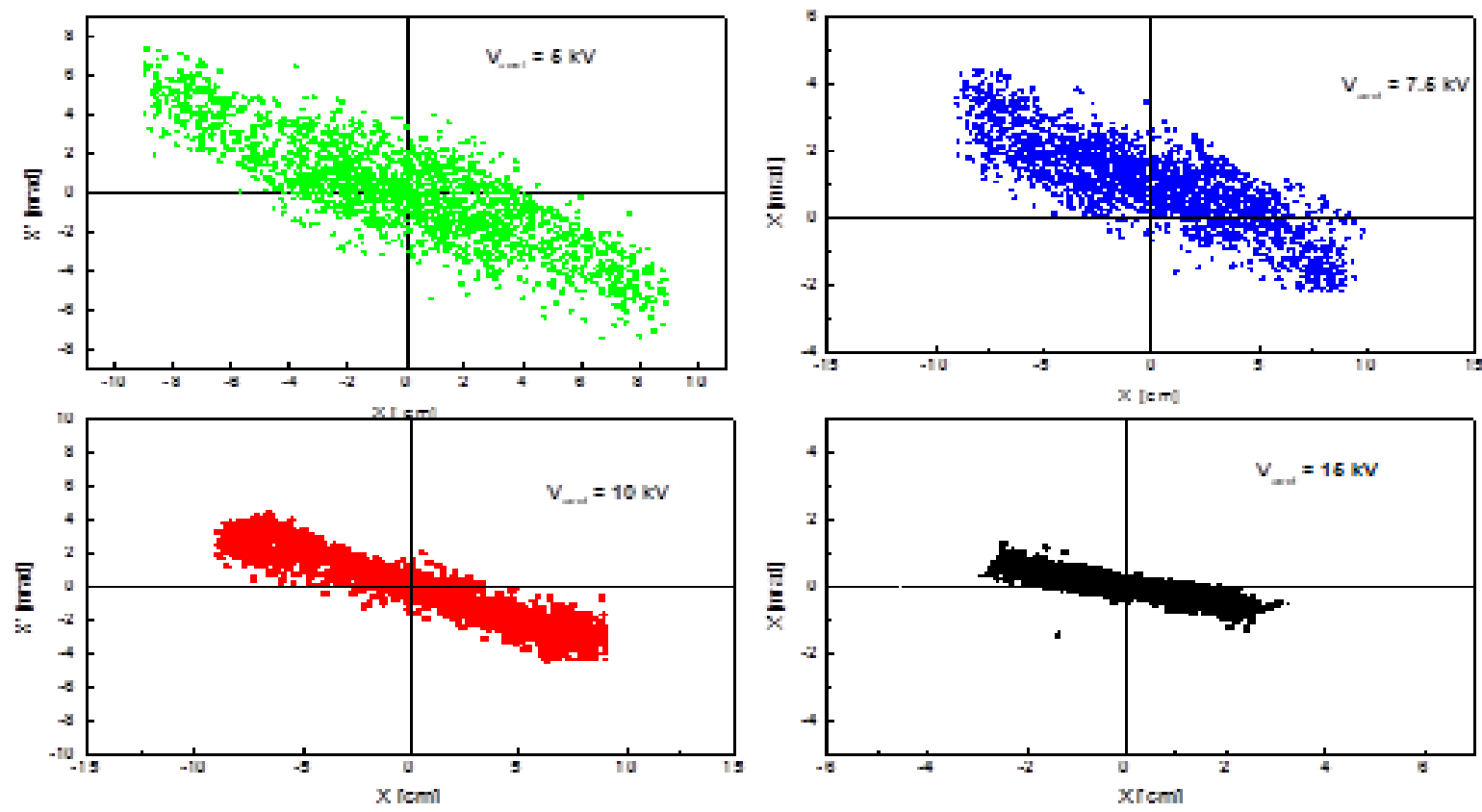

Figure (11) the phase space for different acceleration voltages

The monomer of PET film comprises four functional groups; two ester groups, one aromatic ring, and one ethyl group. The two ester groups with the aromatic ring constitute the terephthalate group which in turn connects to the ethyl group to form the PET monomer. These functional groups consist of many bonds; $\mathrm{C}-\mathrm{C}, \mathrm{C}-\mathrm{H}, \mathrm{C}-\mathrm{O}, \mathrm{C}=\mathrm{O}$ and an aromatic ring. It is well-known that the groups $\mathrm{C}-\mathrm{O}$ and $\mathrm{C}=\mathrm{O}$ in the polymer chain are lacking the resonance stabilization of the phenyl group. Thus, they will interact easily with radiations (neutron/proton/electron/heavy ions) [24-26]. After ion beam irradiation of PET polymer different influences is detected and summarized as follows:

1-In the region between $1500-1000 \mathrm{~cm}^{-1}$ Figure (12), the transmission of the two ester bands (C$O$ located at $1090 \mathrm{~cm}^{-1}$ and $1240 \mathrm{~cm}^{-1}$ ) increases after irradiation.

This behavior proves the existence of oxidation which leads to samples degradation and finally, some cross-links are formed leading to the reduction of the transmission at the highest applied energy $15 \mathrm{keV}$.

2-The oxidation effect is also found in the $\mathrm{C}=\mathrm{O}$ band $\left(\right.$ at $\left.1713 \mathrm{~cm}^{-1}\right)$ which has the same behavior of the $\mathrm{C}-\mathrm{O}$ band and shown in Figure (13).

3- Absorption bands associated with $\mathrm{C}=\mathrm{O}$ bond stretching are usually very strong because a large Arab J. Nucl. Sci. \& Applic. Vol. 52, No. 1 (2019) change in the dipole takes place in that mode and it is responsible for the crystalline phase of the polymer.

4- The cleavage of bonds at the carbonate site releases $\mathrm{C}_{\mathrm{O} 2}, \mathrm{CO}$, and $\mathrm{O}_{2}[22,23]$ which may be trapped and raise the oxidation process during irradiation.

5- Hydrogen atoms may be released in a process known as the dehydrogenation of $\mathrm{C}-\mathrm{H}$ bands leaving carbon precipitations. This behavior appears at the symmetric C-H $\left(2921 \mathrm{~cm}^{-1}\right)$ and asymmetric $\mathrm{C}-\mathrm{H}$ at the knee at $2856 \mathrm{~cm}^{-1}$ in Figure (14) which prove the dehydrogenation effect and the formation of carbon cluster. Carbon cluster is responsible for the polymer color changes and also enhances its conductivity.

6-Carbon cluster may be excited or ionized and attached to the released oxygen species to form $\mathrm{CO}$ or $\mathrm{CO}_{2}$ gasses or enhance the species of $\mathrm{C}-\mathrm{O}$ or $\mathrm{C}=\mathrm{O}$.

7-The released hydrogen and oxygen atoms may recombine to form the hydroxyl - $\mathrm{OH}$ group at $3462 \mathrm{~cm}^{-1}$ and its transmission intensities increase with the ion beam energy as shown in Figure (14).

8-The surface produced changes affect directly its polarity as indicated in this work. The surface polarity is important in wettability and biological applications and enhanced because of the 
DEVELOPMENT OF A RADIO FREQUENCY...

oxygen-containing groups (polar groups) increase.

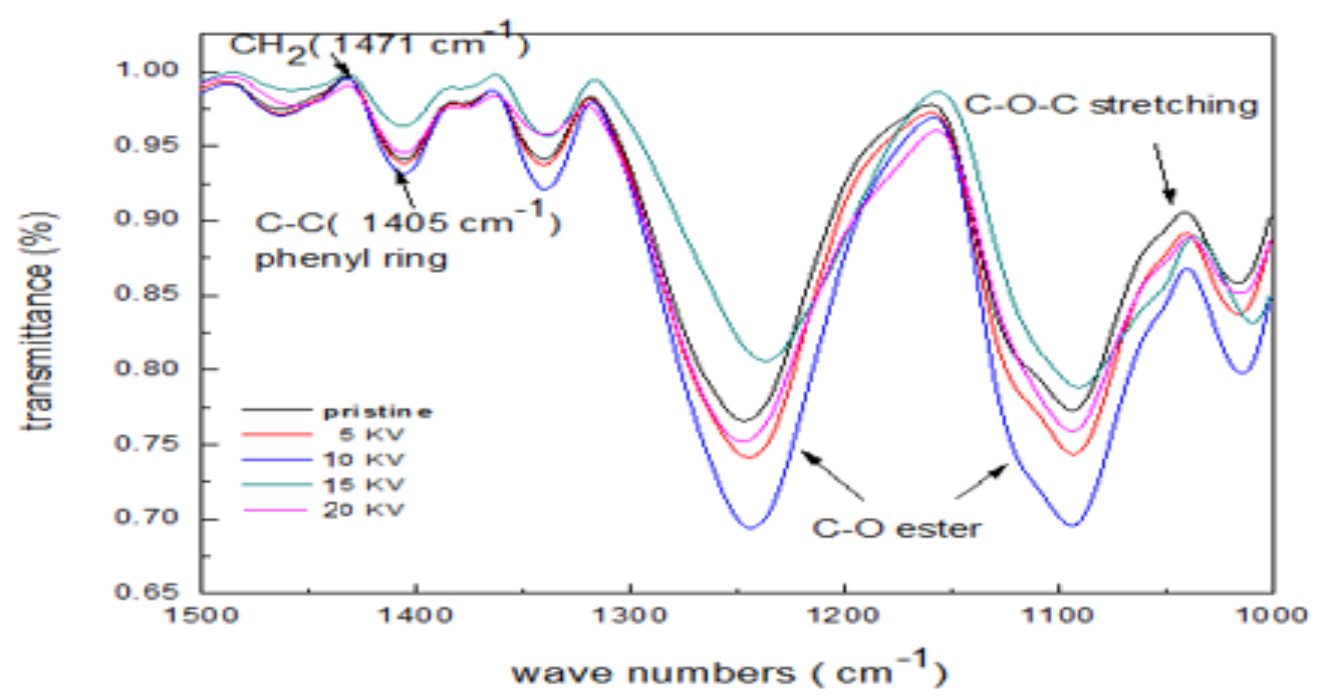

Figure (12) FTIR spectrum of irradiated PET for 1500-1000 wave number

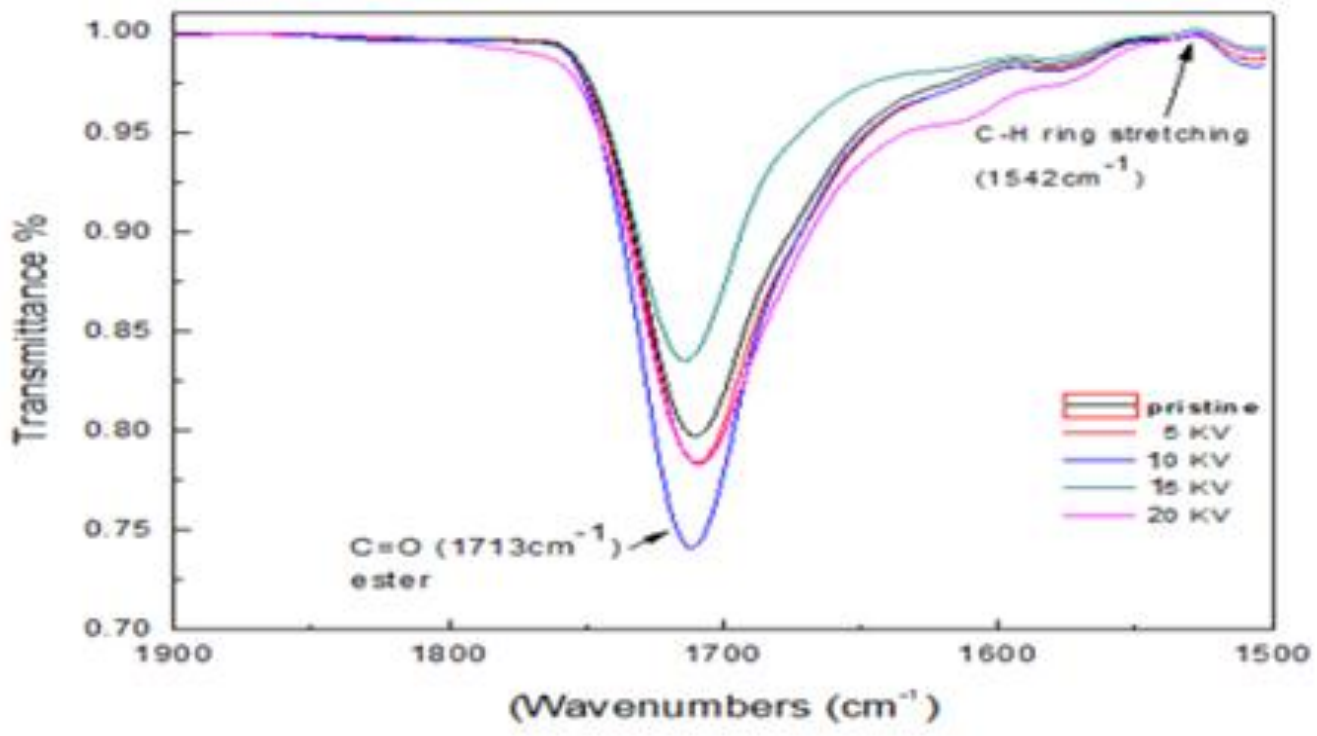

Figure (13) FTIR spectrum of irradiated PET for 1900-1500 wave number 


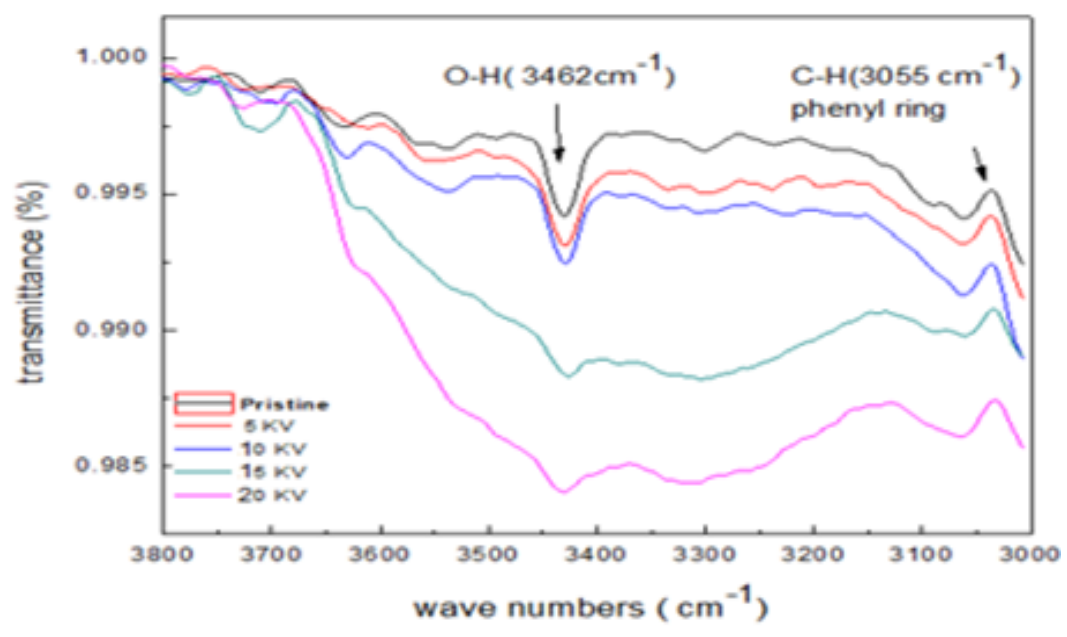

Figure (8) FTIR spectrum of irradiated PET for 3800-3000 wave number

\section{Conclusions}

The design and development of RF broad beam ion source are discussed. The ion source is efficiently able to deliver currents of $100 \mu \mathrm{A}$ up to $30 \mathrm{~mA}$ with extracted voltages from 0.5 to $3 \mathrm{kV}$. The ion source characteristics and OES diagnostics of the RF plasma are investigated. The electron temperature is reduced with the increase in the pressure. This is due to the increase of the energy transferred from the electrons during collisions with the additional gas particles. Electron temperature is reduced with the increase of the pressure. This is due to the increase of the energy transferred from the electrons during collisions with the additional gas particles. The electron density has been estimated from current density and is the order of $1.5 \times 10^{13} \mathrm{~cm}^{-3}$.

Intensive simulation studies using Transport code with graphical interface were performed. The results deduced from the simulation were used to design the beamline to the experimental area. The initial design of the beamline was used as the starting input for the simulations and add an extra solenoid magnet in the drift space before the accelerating tube. The solenoid magnet focused and rendered the beam divergence and emittance growth under control. The PET samples irradiated with Ar+ beams of energies 5, 10, 15 and $20 \mathrm{keV}$ are investigated. The argon ion irradiation of Hostaphane polymer modified its physiochemical properties and improved its surface energy The FTIR spectrometry spectra showed that the degree of destruction of various bonds within the compound molecules increases with the implantation fluence. Formation of carbon clusters composed of $\mathrm{sp} 2$ hybridized atoms is indicated by the presence of wide $D$ and $G$ bands characteristic of the amorphous carbon structures.

\section{References}

1-Pauleau, Y. (2006) Materials Surface Processing by Directed Energy Techniques, Elsevier Science. Ch. 5, 151-204.

2-Hellborg, R. (2005) Electrostatic Accelerators: Fundamentals and Applications, Springer-Verlag Berlin Heidelberg.

3-Kalvas, T. Ph.D. (2013) "Development and use of computational tools for modelling negative hydrogen ion source extraction systems" University of Jyväskylä, Finland.

4-Hassan, A. Elsaftawy A. and Zakhary, S.G. (2008) Nucl. Instr. and Methods in Physics Research A, V. 586, Issue 2, 148-152.

5- Welton, R.F., Carmichael, J., Desai, N. J., Fuga, R., Goulding, R.H., Han, B., Kang, Y, Lee, S. W. Murray, S.N., Pennisi, T.R., Potter, K.G., Santana, M. and Stockli, M.P. (2010) Rev. Sci. Instrum. 81, 02 A727.

6-Abdelaziz, M.E., Zakhary, S., Ghanem, A.A., (1986) Proceedings of $17^{\text {th }}$ International Symposium on Discharges and Electrical Insulation in Vacuum, V, 2 589- 593 12-16 Jul. Berkeley, CA, USA.

7- Abdelaziz, M.E., Zakhary, S., Ghanem, A.A., and Abdelghaffar A.M. (1996) Rev. Sci. Instrum. 67, 1365.

8-Tripathi, S.K.P., Pribyl, P., and Gekelman, W., (2011) Rev. Sci. Instrum. 82, 093501.

9-Rao, Y., Tang, D., Lui, X.and Shen, B., (1990) Rev. Sci. Instrum. 61, 321.

10-Heping Li, Qiuhui Chu, Xin Wang, Peng Wang, Junjie Chai and Zhanxian Li., (2017) Proceedings of the $20^{\text {th }}$ Pacific Basin Nuclear Conference, Springer Science Business Media Singapore, V. 2. 521.

11-Kirill E. Evdokimov, Maxim E. Konischev, Vladimir F. and Pichugin, Z. (2017) Sun ResourceEfficient Technologies 000 1-7. 
12-Cullen, P.J., and Milosavljevic, V., (2015) Prog. Theor. Exp. Phys. 063J01 (17 pages).

13-Whaling, W., Anderson, W.H.C. Carle, M.T., Brault, J.W. and Zarem, H.A., (2002) J. Res. Natl. Inst. Stand. Technol. 107, 149-169.

14-Chapelle, P., Czerwiec, T. Bellot, J.P., Jardy, A., Lasalmonie, D., Senevat, J. and Ablitzer, D., (2002) Plasma Sources Sci. Technol. 11, 301.

15-NIST (2017) Atomic Spectra Database (ver. 5.5.1), https://physics.nist.gov/asd

16-Vitel, Y., Lamoureux, M., Abada, H., Lejeune, A., Faure, C., Tourneur, P. Le., Godechot X., and Cochard, S., (2002) Plasma Sources Sci. Technol. 11, 333.

17-Devia., D.M., Rodriguez-Restrepo, L.V. and Restrepo-Parra, E., (2015) ing. cienc., vol. 11, no. 21, pp. 239-267.

18-Brown., Ian G., (2004), The Physics and Technology of Ion Sources, ${ }^{2 n d}$ edition, WILEY-VCH Verlag $\mathrm{GmbH} \& \mathrm{Co}$. Weinheim.

19-Brown, K. L., and Rothacker, F., (1983) A Computer Program for Designing Charged Particle Beam Transport Systems SLAC-91, Rev. 3 -UC-28
(I/A). http://lss.fnal.gov/archive/nal/fermilab-nal091.pdf

20-Brown, K.L. (1980). Transport, a computer program for designing charged particle beam transport systems. CERN 80-04.

21-Frank Hinter Berger, Physik der Teilchenbeschleuniger und Ionenoptik, p.205-216, Springer, Berlin (1997), in German.

22-Green, T.S., (1976) IEEE Trans. Nucl. Sci. NS, 23 (2) 918 .

23-Hareesh, K., Sen, P., Bhat, R., Bhargavi, R., Nair, G.G., Sangappa, G. Sanjeev, (2013) Vacuum 91, 1-6,

24-Geuskens, G., David, C., (1979) Pure Appl. Chem. 51, 233-240.

25-Sathyanarayana, P.M., Shariff, G., Thimmegowda, M.C., Ashalatha, M.B., Ramani, R. and Ranganathaiah, C., (2002) Polym. Degrad. Stab. 78, 449-458.

26-Joshi, R.P., Hareesh, K., Bankar, A., Sanjeev G., Asokan, K., Kanjilal, D., Dahewale, S.S. and Bhoraskar, V.N., Dhole, S.D. (2016) Nucl. Instrum. Methods B 384, 6-13. 